\title{
Research on Green Space Reconstruction in Interior Design and Application
}

\author{
Song Liu
}

Institute of environmental art, Hebei Institute of Fine Art, Shijiazhuang Hebei, 050700, China

Keywords: Interior design; Reengineering space; separated

\begin{abstract}
The purpose of interior design not only is a decoration and beautification of the interface, more important is according to the different requirements of indoor space reconstruction space, namely the unreasonable interior space reconstruction to be practical, comfortable space. The most important means is to separate the interior space design. Adopts what kind of separation method, should according to the requirements of its space characteristics and function, but also take into account the artistic characteristics and psychological factors, the separation methods to meet different requirements, on the basis of creating aesthetic feeling, appeal and artistic conception.
\end{abstract}

\section{Introduction}

Building and continues today, with the development of human beings is one of the material conditions of people live. Construction in addition to the factors such as the adornment of the appearance and construction details, and the most important things, is through the construction entity to surround close space - space. Space is the most important content, is the embodiment of the architectural function, is the soul of the building. In the past a period of interior space design, designers tend to focus on three major indoor interface the decoration and beautiful, and ignore the use of interior space function. After long time practice and cognition, people gradually realized the purpose of interior design, is not only the decoration and beautification of interface and more importantly, the use function of interior space. As the emphasis of the Bauhaus school "form follows function", advocated abandoning false on the surface of the decoration, the rationality of create space function.

Some architectural interior space can meet the needs of people to function, but there are also many public building interior space and improved interior space, can't satisfy people's needs directly. Reengineering space, it is based on the original building space form of space, to meet people in work and life to the different needs of space function. Separation method mainly has three categories, one is through the physical space, change the size of the specific space, shape; The second is the virtual space, through the material, color, lighting, etc on the impact of psychological; Three is a free space, by using levels of disjunctive space, furniture and decorations. These three methods can be used alone in the design practice and can be used in comprehensive.

\section{Separate Design and Physical Space.}

In be being designed indoors, the purpose of the physical space, are generally use a variety of entities within the relatively broad architectural space, based on the characteristics of human needs, into a specific functions of space fully enclosed space build a make a person feel safe and illicit close space, such as residential bedroom, storage room, display space of the room, Commercial space of the KTV rooms, teahouse, manager's office, the staff lounge, etc. often adopt the method of physical space, in a closed space. Within the closed or relatively closed space, people's perception of space shape is very strong. Cube space, give a person the sense with safe, solemn; Rectangular 
space, give a person the sense with smooth, stretch, open; Polygonal space, can make the person produces the feeling of lively; Atmosphere makes people feel a wide circle space is luxuriant, rich. In actual design, still must according to the specific circumstances of the space, such as size, height, overall structure and the owner's needs, determine how to divide and the selection of material and color.

Semi-enclosed space to meet the various needs, and can improve the utilization rate of space. Semi-closed space is characterized by both around and deeply, make the person feels transformation and circulation of the space, with openness. There are a variety of ways to semi-enclosed space separation.

The Single Space Design. Single split design is to use the vertical surface, the space. This separation is often applied to indoor function is divisional. For example, put a space for the two sizes, make little space with certain illicit close sex, large space to show the openness. Clothing store in interior design, can use the curved screen the angles on one side of the store space into two functional areas, as a locker room inside and outside the checkout counter. As another example, in residential interior design, can use wine ark, dado separates sitting room and dining-room. The entrance hall of the company, you can use steel frosted glass to separate a visitor aisle and space. Single space design can also be applied to cover, works in a similar way.

Chinese garden landscape, make space effect. The entrance of the bar, for example, do a stone, stone middle is glass window. Make people into the bar, produce a sense of time and space conversion. When sitting at the table, listening to music, taste the wine, make people enjoy the temporarily out of the world the hustle and bustle.

The Two Sides of the Space Design. This way of separating generally there are two ways, L and parallel space. This separation is often applied in the exhibition space and office space. L space available to a variety of plate for vertical interface, two phase of forming Angle, generally for the 90 - degree Angle, can also form an obtuse Angle according to need. Field Angle sense is very strong, have intimate feeling. Such as studio, Angle place to set up the dressing room. Do L space inside the exhibition hall, can negotiate the formation of space Angle. In the scriptorium 1-shaped space, sofa is put in the Angle of place, water machine, became a office space and relative isolation of staff locker room. This separation is both spatial segregation, and liquidity, orientation, is advantageous to the interpersonal communication. But the back Angle of exclusive, have the effect of regional space.

Parallel space, will be formed in the interface between areas. Western restaurant, coffee shop often take short interface multiple parallel space, form the orderly dining space. If parallel space interface, the interface between formation channels, has a clear direction. In office or commercial space do so separated.

The Three Sides of Space Design. Three sides split design is also called u-shaped space design. This separation is characterized by the circle of three sides of the area, personal feel strong, open side of a space of liquidity and the communication with the outside world. This separation is common in large office space.

\section{The Space Design of Virtual Space}

The virtual space is known as the "psychological space", there is no clear separation condition, is depend on people imagine to divide the space. Or no physics in integral space face space for physical space, but the use of interior decoration materials of different texture or color difference, the lights of the intensity of light and color difference, make the person's psychology produces 


\section{different space impression.}

Use Color Space Design. "Far see color, almost see form", we live in a environment, each object has its own color and shape, but is most sensitive to impact our visual color, followed by shape. When we use color separation, should first understand all sorts of all sorts of color gives a person to produce the effect of physiological and psychological changes, to achieve the target, just right. The psychological impact of different colors to us is not the same, mainly through the changes of color changes in temperature, light and shade and pure grey changes to reflect. According to the color on the psychological and physiological.

Effects, the use of metope, ground, the furniture of different colors, particular in different areas of the indoor atmosphere, or display a division, which makes people feel the change in the space, or aware of the functional partition.

Use of color to a broad space for the virtual space, and they are widely used in the commercial space or public space can have multiple effects. Use of floor tile color difference, has not to undermine the space overall unity, and shows the characteristic delimited area. Such as in the large shopping malls, floor tile of different colors, can be divided into different sales regions, and make the customers have no obstacle in the flow, wide vision, very conducive to build commercial atmosphere. As another example, in the business building of the hall, floor tile of different color or pattern symbols, can have the effect of direct customers.

With metope colour difference divided into different areas, is easy to make whole space shows clear space, to attract the attention of people. Children's entertainment, such as commercial building, use bright, bright colors and other sales area, not only can let the children of euphoria, improve the interest of children, the parents also facilitate complex business district to find this special area. As another example, the fast food in the commercial building area with orange metope to attract customers.

Use Material Space Design. Using ground or metope material changes in the form of virtual space, widely used in interior design. Such as residential interior design, in a porch place that take the door, usually use stone or tile floor. Because this is the place where people really change clothes in shoes. Porch is the ground of wear-resisting, and easy to clean up than in other places. The sofa of the sitting room before placing a carpet, make people not only their feet up feel comfortable, also produced a remarkable times feeling is sweet the coexistence of space. Some high-end beauty salon, glass on the floor to the operating room, under the glass is colorful rubble, and hit the lights, exquisitely carved, and create a wonderful effect of the pursuit of beauty, charm of metaphor and beauty, and elsewhere in the stone material ground form contrast.

Metope material can also cause the simple sense of the space effect. Bar often use metope material difference, the division of regional performance services and consumption. In the business hall, a wall in the simulation of the decorative stone art, arrangement of greening plants according to the wall, make indoor produced an area full of natural taste, also add the cultural implication. Chinese restaurant of one side wall design for the jiangnan style of a beautiful window as opposed to a storefront window, in the person produce psychological modern history with a blend of two kinds of space. Of course, when we use different materials for space reconstruction, should fully understand the basic features of all kinds of material, can skillfully use it. One of the basic materials of wood as a building, its material is qualitative light, natural grain is beautiful, visual and touch the warmth, have very good elasticity and toughness, and easy processing, for electricity, heat has very good insulation. But the downside is soft in texture, not wear-resisting, so often and stone collocation is used. Two kinds of stone material is divided into natural stone and artificial stone. We often use in interior design is the granite and marble. Using natural marble, very beautiful, but in 
less than a year, the ground was been east to west, refute. This is mainly because the marble belongs to metamorphic rock, fine, color variety, there are beautiful natural color, but it is the biggest drawback is not wear-resisting, easy to weathering, so only suitable for indoor metope act the role of material. Granite belongs to magmatic rocks. The characteristics of compact structure, high hardness, wear resistance, pressure, refractory and atmospheric chemical corrosion resistance. Have the laudatory title of "stone rotten to be one thousand". More to the ground and inside and outside wall act the role of brick. The disadvantage is that color pattern. It seems that when we choose stone, must certainly grasp the characteristics of it clearly.

Use transparent glass as the material of disjunctive space, can produce the dimensional feeling of a kind of bricks. The biggest difference between glass and other building materials are transparent, at the same time, the glass, and the function of sound insulation and heat preservation. With glass interior space separation materials, has a unique effect. Some modern company's conference room with glass walls, not only ensure the meeting undisturbed, and shows the company's openness and transparency of the decision-making. Modern shopping malls with glass in the one horn of the sales hall separated the rest area, enables customers to temporarily avoid the busy shopping area to enjoy a moment of quiet, also to communicate and shopping area, good produce continue consumption desire. In glass disjunctive space, has the characteristics of internal and external space is connected fully integrated.

Use Light Space Design. We usually divides into the light of natural light and man-made light two kinds. Natural light is mainly refers to the sun, also known as the skylight. Artificial light is used for lighting of all kinds of lights. Although the skylight uniform light cloth, visual comfort, but due to the influence of the weather, uncertainty. So the indoor lighting is heavily dependent on light. Indoor lighting in addition to the basic function of illumination, and foil image, atmosphere, and produce the function of the new space. Can make the light space function is mainly by the changes of the difference of the light intensity of illumination and color temperature.

Illuminance (LX) refers to the strength of the light on the object. Intensity of illumination and light power and irradiation direction and distance has a direct relationship. Illuminate light source of high power, the distance of the object, the intensity of illumination, high brightness. On the contrary, intensity of illumination is small, low brightness. Depending on the intensity of illumination is different, resulting in a different light and shade space change. Refers to the changes in temperature changes the light color temperature, we use the type of light source are mainly indoors fluorescent lamp and incandescent lamp. Fluorescent color slants cold warm, close in color. Incandescent light warm color temperature. [1]Another is inside the bulb into all kinds of inert gas, resulting in a different color of color bulbs. In fact no matter what kind of light color of orientation. This use of different colors of light to create different space atmosphere. For example, in the lighting design of the coffee shop, guest room with moderate, low intensity of illumination light build static and hidden areas of the public space, make the guest feel relax, and let the audience set up bright reflection light, signal bar is a public service, and make the person is easy to see it.

Light to the virtual space not only, still have a certain space orientation, such as alive general merchandise, on the second floor is warm orange sales areas of lamplight, creating a warm and comfortable shopping space, aisle lights for cold cyan, thus a guidance in the virtual space, make people follow the light can find various export sales areas.

Use Water and Green Space Design. We live in the "forest" of modern reinforced concrete, the tense and busy, life, tired, depressed and always want to relax, eager to blend in the "green village, castle peak guo external oblique", "hanshan far water jiang village, and shaped into ink screen" natural landscape, feeling the landscape. Water can reduce the dust in the air, increase air humidity, 
reduce the temperature of the space. The voice of water flow and the impact and can edify sentiment, make people get beautiful enjoyment. Green can adjust the person's vision, to the optic nerve play the role of a relax and rest. Green plants can regulate air temperature, humidity and flow state, and can block, absorb dust, reduce noise. In interior design, therefore, tend to move within the exterior, with water or plant disjunctive space, make people never leave home, can realize the landscape of nature.

With Transparent Partition Space Design. Refers to the form of a single partition separating the interface of interior space, is usually fixed, such as screen, screen wall, etc. Separated interface such as entity, not fully, we have introduced in the semi-enclosed space in front of, here only talk about appear a partition of the space design.

Use of the space appear a partition to separate, connecting and permeability is very strong, sometimes just a virtual interface. Such as the partition of the Chinese traditional "cover" and "rich ancient frame. "Mask" is the upper or the schematic is made on both sides of the space, the open in the middle of the partition. In accordance with the "mask" in the interior is divided into many different shapes and the location of the ground cover, aureole cover, cover, star anise, and other forms. Rich ancient frame, also known as dado, by fully, different height of lattice layer upon layer, used to display the adornment such as antiques, porcelain, both sides can be for people to enjoy, used for large space residential sitting room and study more, of primitive simplicity, elegance. In the modern Chinese style to decorate plan, we often can use all kinds of traditional forms of partition. Sometimes used in the whole scheme, sometimes in the form of local, aims to reflect culture, apply colors to a drawing the atmosphere. With the continuous innovation of modern design consciousness, increasing material varieties, partition will also be in the form of more and more.

\section{Free Space and Space Design}

Free space more flexible, gimmick is diverse, generally using the method such as decorations, furniture and level difference for space design.

The Level of Space Design. In the same plane of matrix space, in order to highlight the subspace, we limit to use the ground elevation difference changes to achieve a goal. Because raised floor space than no rising space is easy to arouse people's attention. Level elevation difference in addition to the dramatic change, there are very strong, space finite. Because commercial space is a relatively independent area, personality is very strong, so, many manufacturers in the market to raise their own area, and stack height difference change, form a finite strong sales areas. As in the Haitian restaurant, the window of the ground, then create an independent, warm dining area.

Use Furniture Space Design. In the interior space environment, people no longer regard furniture as independent one, but the furniture is regarded as part of the whole space design, namely in the process of interior decoration, furniture design and production together with the indoor environment. Furniture is become by the combination of body, in the indoor environment, occupy a certain area of space and capacity. Therefore, in a lot of design, designers tend to put the furniture as the furniture partition, to separate and create a new form of space, create new features, to meet the different requirements of people. In the household, restaurant, office and other space, the use of furniture for separating case. Because of different combinations of different furniture, separated by a space character is different also.

Use Decorations Space Design. Decorations, also known as furnishings, the main role in indoor environment is to strengthen the visual effect of interior space, increase the environmental quality of character and artistic taste, have the effect of the chief use for delight sent, edify sentiment. [2]A 
wide range of accessories, a wide range, big to indoor, fountains, flower bed, small to antiques, pottery. Each decoration has its own scale, modeling, color and texture. You should be careful when we choose. In the use of accessories for disjunctive space, choose the decorations scale and size must be larger, because the decorations with small space, won't produce dimensional feeling. Choose much more appropriate of the scale of the decorations, it depends on the size of interior space scale, because the relationship between them is proportional. When we choose accessories must be coordinated and indoor style. To adopt the method of comparison, decorations must be fewer but better, not too conflict style.

\section{The Origin of Indoor Greening Design}

Indoor greening has a long history. With the development of urban and suburban construction, green space. People has a natural nostalgia for the lost green space. Especially living and working in the multi-story or high-rise building room around within the people, the more eager to have a green environment. Plants in the case of light can make the air fresh, also can adjust the humidity, plant green is a kind of downy color, can give the stimulation of the cerebral cortex to good, can make the fatigue of the nervous system after intense work and think relaxes and recovery; Flowers plant with its full, more various and beautify the indoor environment, add interest, give a person with beautiful enjoyment.

Indoor afforest is part of the interior design, and interior design closely linked. Mainly using plant materials combined with the interior of the shape, size, use garden commonly used gimmick, organization, perfect, beautification, downy occupied space, coordinator of the relationship with the environment.

The Function of Indoor Greening Design and Function. Beautify the indoor environment greening on the indoor environment beautification function mainly has two aspects: one is the beauty of the plant itself, including its color, shape and fragrant; It is through the plant combined with indoor environment properly, organically configuration, from the aspects of color, shape, texture, etc to produce bright contrast, to form a beautiful environment.

To Purify the Air and Regulating Indoor Microclimate. Modern science has proved that greening has quite important ecological function. Good indoor greening can purify indoor air, adjust the indoor temperature and humidity, beneficial to human body health; Plants absorb carbon dioxide during photosynthesis to evaporation, release oxygen, some plants can absorb the harmful gas, secretion and sexual material, kill the bacteria in the air.

Edify Sentiment, Cultivation of Body and Mind. Most of the time is spent in indoor, indoor environment closed and drab, can make people lose the closeness to nature. Human instinct of nature have a strong yearning. This desire can be done by indoor afforest, because the plant is a product of nature, the most can represent the nature. Indoor greening design, introduce the nature flowers and plants indoors, make the person as if place oneself in nature, so as to achieve loosen body and mind, maintain mental health. In addition, people in the indoor virescence maintenance and management of the process also can edify sentiment, cultivation of body and mind.

Indoor Greening Design Layout Requirements and Forms. Green plants to beautify the indoor space to conform to the laws of art, can't get in the way of daily indoor activities, plant layout should be formed with the surrounding environment as a whole. Select plant and plant height should be according to the size of the architectural space. The growth of plants in order to satisfy the reasonable space and light conditions, and satisfy people's visual perception, the height of the plants is generally not more than two-thirds of space height, otherwise, will cause the space 
depressive feeling.

The layout of the indoor greening design can be summarized as dot, line and three basic layout form. Dot distribution is independent or group concentrated arrangement, often decorate in the important position of interior space, become the focus of visual and size, posture, and colors of the plants used to have a more prominent ornamental value; Line layout is the plant into a linear, its main function is to guide line of sight, divided into interior space, as a symbol of space interface, choose plants to unify, can be the same kind of plants into linear arrangement, can also be a variety of plant staggered into a linear arrangement; Surface is into pieces on the layout arrangement, and the emphasis on quantity is big, the background of the mostly used as interior space greening, foil and foil effect, it emphasizes the overall effect, so, should be considered in the body, shape, color, etc, the overall artistic effect [3].

Indoor Greening Design of Plant Selection and Display. Indoor Greening Design Plant Selection. Light is the main factors that affect plant growth and development, indoor greening plants to consider the choice of suitable for plant growth and normal need to light, temperature and humidity; Plant size corresponds to a size, different size of space to choose a different dimension of plant material; Plant morphology, texture, colour wants to be coordinated with the purpose of the room, such as the study configuration such as asparagus, orchids, can make the space appears elegant and quiet. Indoor greening plants to choose appropriate container design, USES the appropriate way of display, plus the light irradiation and artistic processing. Indoor greening design of plant cultivation of container is divided into ordinary planting basin, basin and planting groove three types.

Indoor greening design plants generally can take the display as follows: on the floor (suitable for larger potted plants, especially the form, structure of plants); Furniture or windowsill (suitable for relatively small potted, because only put them at a certain height, can obtain good viewing Angle, thus has ideal ornamental effect); In independent type base (suitable for a long, drooping leaf plants. In order to coordinate with the style of interior decoration, can choose pseudo-classic style base (such as root base), or concise form vertical gypsum base, glass fiber reinforced plastic imitation plaster base; hanging from the ceiling (suitable for branches drooping plants, such as bracket plant, bird's nest ferns. Suspension can make drooping branches grow shine, and the most easy to attract the line of sight of people, special effects); suspended on the wall (suitable for trailing plants and small flowering plants. Trailing plants are commonly used to draw the outline of the window profile, flowering plants with its gorgeous colors and the metope of quietly elegant contrast).

Light Processing. A lighting on the one hand can improve plant light conditions, promote plant growth; On the other hand can create a special atmosphere at night. Lighting the way into the projection lighting, lighting and back lighting up. Upward lighting way is to put the lights in plants, the main purpose is the special effect of shadow on the wall; Back lighting is hidden behind the plants, the lights make the plant under the condition of the backlight produces dark outline, exquisitely carved effects.

Different Greening of Bedroom Space Layout. Dr. D.G Hess yon decoration household plants can be divided into six regions, according to statistics, $79 \%$ of households put plants in the living room, $51 \%$ of households put plants in the kitchen, $34 \%$ of households put plants in the porch of the gate and the stair well, $28 \%$ of households put plants in restaurants, $12 \%$ of households put plants in the bathroom, $11 \%$ of households put plants in the bedroom. According to the author's observation, ordinary Chinese afforest decorate the space order of priority is: the bedroom of the balcony, sitting room, dining-room, bedroom.

The Sitting Room is Green. The sitting room is the main place of daily life, the space is 
relatively large, so the afforestation of the sitting room decorate should become the focus of the bedroom is green. Single function the display of the main of the sitting room is sofa, chairs, tea tables, TV, acoustics, etc. To afforest decorate should pay attention to the quantity, variety should not be too much. A bigger space of the sitting room, can be placed at the entrance of flower arrangement, miniascape, greeter effect; Can be placed two basin is relatively tall araucaria in the middle of the sitting room, cycads, to break up a space; Corner cabinet can be placed, the window beside the bamboo of curvature of the spinal column, rubber tree, bamboo, etc. Multi-function hall to both the role of the sitting room, dining-room and even study, its main position usually arrange sofa, talking with tea table of center again. Can put potted flower by sofa, tea table on flower arranging, corner can decorate a large potted plants such as rubber tree and the other, can also be used to break up a space, plants were isolated talks, dine, learning space, etc. Plants do not centered, with slightly on one side is preferred. Pay attention to the rich space level as far as possible, small plants can be put in mesa, large plants on the ground and the vertical plant suspension. In addition, the plant should also pay attention to color texture and indoor tonal collocation. If the environment is tonal, dense tonal should be treated by some plants.

The Balcony, Windowsill Greening. The balcony of type opening open that is a good rest and looking place, with strong area through reasonable afforest decorate can make the person as if place oneself in the natural environment; If combined with cage and water cluster cases, the effect is more ideal. Decoration area is smaller through different kinds of medium and small potted, or in the roof hanging plant, also can create good landscape effects. Window it is a good place for arrangement of greening, hanging greening plants on the window sill, can soften the monotonous rigid construction line, make its show alive and vibrant. If set on the window sill planting groove, groove colourful four seasons of flowers and plants and small shrubs, the effect is more ideal. An important part of balcony afforest, promote appetite, harmonious relationship.

Table of Plant Design. The design should not be multifarious, concise, a bottle of flower arrangement. [4] Landscaping bedroom should create a quiet, sweet, leisure and comfortable atmosphere, relatively capacious bedroom can use standing type large pot; Hanging potted small bedroom can choose, or plants on the fine set of basin after put on the dresser or windowsill.

\section{Indoor Greening Design Way}

Way of indoor greening design in addition to depending on the materials of the plant morphology, size, color and ecological habits, but also on the basis of the size of interior space, the strength of the light and the seasonal change, and the atmosphere. Its design methods and various forms, including display, clings to type, suspension type, wall hung, plant type, and the design of the miniature foliage plant greening.

Display Greening Design. Display is the most common indoor greening design and the most common way of design, including point, line, and the type 3 kinds. Of which point is the most common, the potted plant on the desktop, tea table, GuiJiao, windowsill, and a corner, or in the indoor air suspension, a green viewpoint. Line and the chip is a group of potted plant is put into a line or organized into freestyle, rules of flake graphics, rise to organize interior space, to distinguish the different USES place indoors, or combined with furniture, have the effect of dividing range.

Type Greening Design. Halls and restaurants, such as indoor areas need to split, with belt clings to plant quarantine, or the fence with a bar or design decorative pattern to provide clings to plants and clings to coordinate in shape, color, material, etc. In order to make reasonable interior space division, coordination, and practical. 
Hanging Greening Design Trailer. Large indoor space, combined with the ceiling, lamps and lanterns. Put it beside the window, the corner, the furniture has a certain volume of Yin hanging plants, improve the indoor artificial buildings as dry as a chip and drab feeling caused by the hard line, build a lively space stereo aesthetic feeling, make full use of space.

Wall Greening Design. The beautification of greening indoor wall, also is popular among people. Wall have hang wall hanging, hanging wall managed to put, recessed method and window method. Advance on the wall set up local uneven hole wall and wall, for placed potted plants; Or flowers is placed in the ground, or planting groove, build by laying bricks or stones and then grows on plants, make its growth along the wall, form indoor local green space; Or on the wall to set up support, in the case of do not take up the place flowerpot, to enrich the space.

Plant Type Greening Design. This design method is used for indoor garden and indoor large hall has sufficient space. Planting, use more natural type, namely the plane dependent accumulation and dispersion, density, and shrubs and herbs and cover plant level, and the harmonious collocation of style, color, proper attention to use the color of indoor foliage plants to enrich the landscape image; Consider with rocks, combination of waterscape, landscape into at the same time, the simulation of nature landscape [5].

In short, in the design of many projects, separation method often used by more than one, but several methods used at the same time. Different space change is very delicate, sometimes virtual space into a closed space. Such as vertical pillars on the ground, it has no direction, the space around all pillars as heart point, virtual out a circular space. Such as plus a pillar, the virtual one between these two pillars can be a qualified, post continuously increasing, and form a entity. Four pillars standing on the ground, will be a virtual one square space, such as increasing the arrangement of columns, can form a closed square space again.

It seems that we are separated by space, must pay attention to the reasonable use of separation methods, made it practical, comfortable and beautiful space. With the progress of science and technology, building diversified and lifestyle of the rich in the information age people, will further promote the development of interior design. In a word, the interior space of reengineering is the designer should focus on problems in the design practice.

\section{References}

[1]Chen Song. 100 kinds of healthy indoor plants [M]. Harbin publishing house. 2008

[2]Lai fengwen. Interior design principle [M]. China building industry press. 2006

[3]Li Lairong. Indoor foliage and decoration [M]. China forestry publishing house

[4]Li qing. Modern afforest adornment of the bedroom [J]. China's health issue. 1996

[5]Li Xiao. Indoor layout and configuration [M]. Background of science and technology news, 2000 